\title{
"Colorir o passado com o presente": proposta de construção e apropriação de memória no projeto Juventude, política e religião: diálogos intergeracionais
}

Priscila Vieira Souza

Pesquisadora Associada da School of Arts, Birkbeck College (University of London) Doutoranda em Comunicação e Cultura (Universidade Federal do Rio de Janeiro) Rio de Janeiro, Brasil priscilavieira@ufrj.br

Marcus Vinicius Matos Doutorando em Direito pela School of Law, Birkbeck College (University of London) Londres, Inglaterra mdemato1@mail.bbk.ac.uk

\begin{abstract}
Resumo Análise de projeto que grava em vídeo depoimentos de líderes evangélicos perseguidos pela ditadura militar, com o intuito de que jovens da atualidade tenham contato com esse material. Utiliza reflexões de Michael Pollak e Maurice Halbwachs, e as relações entre memória e temporalidades contemporâneas tecidas por Andreas Huyssen e Martin-Barbero. São percebidas disputas de identidade e pertencimento dentro do grupo e no contexto amplo da história oficial/ memória nacional.
\end{abstract}

Palavras-chave: memória, direito à memória, videodocumentário, religião, juventude.

\section{Introdução}

66 Tuventude, política e religião: diálogos intergeracionais"1 é um projeto de elaboração e apropriação da memória de líderes evangélicos das décadas de 60 e 70 do século passado, que participaram da atuação política naquele momento do país. Foi iniciado em 2005, com a gravação de depoimentos de sete pessoas que atuaram no contexto referido. Em 2007, teve o seu primeiro produto divulgado: o curta-metragem "Cristo e o processo revolucionário brasileiro", com a edição da entrevista ao sociólogo e pastor evangélico Waldo César. ${ }^{2}$

1. O projeto completo e em sua versão atual, encontra-se disponível no site do Instituto de Estudos da Religião (ISER): http://www.iser.org.br/site/projetos/juventude-politica-religiao -uma-abordagem-dialogica.

2. A informação de que o sociólogo Waldo Cesar foi pastor evangélico causa espanto no meio acadêmico em geral. Mesmo nas mídias especializadas - como em entrevista realizada pela revista evangélica Ultimato -, geralmente Waldo é identificado apenas como "presbítero luterano". No entanto, em sua entrevista concedida em julho de 2005, no referido projeto, e 
O documentário mescla falas do personagem com matérias da época, produzidas pela Agência Nacional, do governo federal. O que chama a atenção em "Juventude, política e religião...", além da busca por construir a memória política do protestantismo brasileiro, é a proposta de interação dessa memória com a juventude evangélica atual.

A primeira inovação do projeto foi produzir material audiovisual em mídia digital sobre o período, possibilitando a difusão dessa memória para além dos livros e do público acadêmico. Essa proposta tornou-se, porém, uma limitação ao seu desenvolvimento, por causa dos altos custos de produção e edição do material, o que acarretou longos períodos de intervalo nas gravações para captação de recursos. As dificuldades financeiras enfrentadas pela equipe levaram o projeto a ter três fases distintas: a primeira, sob o título "Diálogos Intergeracionais: evangélicos, memória social e formação de lideranças", foi financiada pela ONG Visão Mundial, pelo Movimento Evangélico Progressista (MEP) e pela Basileia. A segunda fase, que surge com maior ênfase no tema das políticas públicas de juventude e nos processos de recomposição da juventude evangélica progressista, foi executada em parceria com o ISER, a Rede FALE e o Movimento Ecumênico de Estudantes de Teologia (MEET), e obteve financiamento da Fundação Luterana de Diaconia e da World Student Christian Federation, ligada ao Conselho Mundial de Igrejas. A terceira fase, em 2013, consistiu na digitalização e edição do material coletado, e encontrou apoio nos processos de resgate da memória instaurados e fortalecidos pela instalação da Comissão de Memória e Verdade no Brasil, pela Presidência da República. É possível que o material produzido contribua para o processo de resgate da participação política das igrejas durante a ditadura militar ${ }^{3}$ instaurada no Brasil em 1964.

A segunda inovação ${ }^{4}$ do projeto é a proposta de transitoriedade entre instituições e campos religiosos que, em tese, podem ser considerados separados, institucional e teologicamente. Ao procurar estabelecer o resgate da história do protestantismo e do evangelicalismo brasileiros como oriunda de uma raiz comum, o projeto transita entre o movimento ecumênico e diversas organizações da juventude evangélica brasileira, permitindo a reconstrução da identidade e da história desses grupos. Trata-se, sem dúvida, de uma pesquisa engajada - como explicaremos a seguir -, que procura reconstituir essas identidades históricas a partir de narrativas que foram seletivamente excluídas das histórias oficiais de igrejas e instituições protestantes e evangélicas no Brasil.

Em sua primeira elaboração, no período de 2005-2007, o projeto propunha fazer a interação dos jovens com essa memória a partir de grupos focais, que seriam realizados mediante exposição dos vídeos gravados com os entrevistados a jovens posteriormente selecionados, seguida de debate. Em sua reformulação para o período entre 2009-2011, o projeto previa que jovens evangélicos do século XXI, politicamente atuantes - nas esferas local, regional ou nacional -, assistissem aos depoimentos gravados em vídeo e selecionassem trechos a serem editados em pequenos curtas, empoderando esses grupos para a edição do material audiovisual. "Juventude, política e religião..." teve uma segunda fase de gravações durante o ano de 2010, em que o roteiro previa o início do trabalho com os jovens para março/abril de $2011 .^{5}$

Outra peculiaridade do projeto é a metodologia empregada na dinâmica das gravações. Para cada entrevistado foi convidado um grupo de entrevistadores, escolhido com a finalidade de ser heterogêneo quanto à área de formação e denominação cristã a que pertencia (em geral, todos possuem alguma filiação religiosa). Normalmente são pesquisadores profissionais ou em formação, ou seja, já possuem pós-graduação ou são mestrandos ou doutorandos. $\mathrm{Na}$ primeira etapa, em 2005, a maioria dos entrevistadores selecionados atuava como professor do ensino superior e pesquisadores. As entrevistas são realizadas com o recurso de um roteiro temático, bastante focado na Confederação Evangélica Brasileira (CEB) e no evento por ela realizado em 1962, que ficou conhe-

editada como filme curta-metragem, Waldo revela que foi pastor da lgreja Presbiteriana do Brasil, cassado por intervenção da cúpula da igreja em 1962, processo a que se refere como "um golpe antes do golpe". Finalizado e distribuído a partir de novembro de 2007 , o documentário não foi visto pelo personagem, que faleceu em setembro do mesmo ano. Naquele momento, o projeto ainda não havia definido a forma posterior de interação com a juventude, oferecendo-lhe a edição do material, como elaborou na segunda etapa, em 2010.

3. Entre as poucas matérias jornalísticas publicadas sobre o tema, é interessante ver: "Os evangélicos e a ditadura militar" (Cardoso, 2011), publicada por ocasião da remessa de documentos do projeto Brasil: Nunca Mais para o país.

4. Embora inovadora, essa proposta não é original, uma vez que outros empreendimentos do meio acadêmico e teológico apontam no mesmo sentido. Ver: Longuini Neto (2002).

5. Esta informação foi obtida informalmente no Instituto de Estudos da Religião - ISER, que é um dos principais realizadores do projeto. Os autores desta reflexão acompanharam as gravações de 2010 e atualmente (2013) colaboram com o processo de edição. No entanto, devido ao realocamento de recursos necessário para a finalização da gravação de entrevistas e edição do material, essa etapa foi diluída no momento, cuja maior ênfase está no caráter documental do material, que poderá colaborar com a Comissão Nacional de Verdade, especialmente no recorte da participação política de igrejas no período da ditadura militar 1964-1985. 
cido como Conferência do Nordeste, sob o polêmico título "Cristo e o Processo Revolucionário Brasileiro". Quase a totalidade dos entrevistados contribuiu de alguma maneira para a conferência, ou esteve presente.

Indicações e apontamentos sobre essas caracterizações do projeto serão realizadas logo na primeira parte, em que se procura mostrar como "Juventude, política e religião..." foi construído para ser um projeto de apropriação de memória, e não de reconstituição do passado. Nesta parte, observam-se conceitos elaborados por Maurice Halbwachs, que ajudam a compreender esta proposta e a possibilidade de ela atingir seus objetivos. Também são colocadas algumas considerações de Cássio dos Santos Tomaim (2009), que possui um material semelhante, com documentários como "Vlado, trinta anos depois". O diálogo sobre as questões da memória desenvolve-se com a imersão das questões levantadas pelo projeto, aqui analisado em textos de Michael Pollak (1989, 1992), cuja expressão inspira o nome do artigo e guia toda a reflexão realizada.

Segue-se, então, o questionamento sobre as possibilidades da proposta de apropriação das narrativas das personagens selecionadas pelo projeto, tocando questões como a formação de identidade e os riscos que advém do uso destas memórias. Por fim, anexa-se ao trabalho breve reflexão sobre o meio, o vídeo enquanto possibilidade técnica de abrigar o encontro entre passado e presente. Considera-se que esta parte suscita questões que podem ser exploradas em trabalhos futuros, mais especificamente sobre as temporalidades contemporâneas. Para tanto, Andreas Huyssen (1997) e Jesús Martin-Barbero (2000) são importantes contribuições. Como apontamento, percebe-se que o projeto revela tensões entre relações internas do grupo e inserções nos contextos amplos das disputas pela construção da memória nacional.

\section{2. "Juventude, política e religião...", uma proposta engajada}

A abordagem reflexiva de "Juventude, política e religião: uma abordagem dialógica" exige a percepção de que não se trata de uma proposta ingênua, do ponto de vista da relação com o passado. $\mathrm{O}$ próprio texto do projeto evidencia que o passado foi pensado como construtor e promotor de memória. Já no resumo, coloca-se que a proposta

procura produzir subsídios de formação para organizações sociais que trabalham no campo da promoção de Políticas Públicas de Juventude. Para atingir seus objetivos, propõe a realização de um resgate histórico da atuação política da juventude cristã nas décadas de 1950-1960, principalmente no âmbito da Confederação Evangélica do Brasil (CEB) e da Aliança Cristã Acadêmica (ACA). Através do uso das novas tecnologias, busca construir uma abordagem dialógica entre as organizações de juventude religiosa atuantes e esta memória, fornecendo a estes jovens recursos audiovisuais e de formação com os quais possam interagir. ${ }^{6}$

Assim, a intenção de que a juventude atual se aproprie e elabore a memória captada pelas entrevistas fica clara logo no início da proposta. Vale ressaltar, sobre o engajamento na construção/elaboração de memória no meio protestante, que a proposta foi elaborada por atores que desempenham funções em organizações protestantes de juventude da atualidade e possuem alta formação acadêmica nas áreas sociais. ${ }^{7}$ Disso é possível inferir duas percepções: a primeira, que o projeto nasce da inquietação com as histórias de vida daqueles que atuaram em sentido parecido, mas há algumas décadas, com a perspectiva de que no passado outros jovens percorreram o caminho da intersecção política-fé no meio protestante, no contexto em que viviam, e, em alguns casos, sofreram graves consequências por isso, tanto no meio secular quanto dentro das próprias igrejas. A segunda percepção é a de que há no projeto a preocupação de fazer emergir e propagar o que estava oculto, silenciado, o que era ruído. Essa intenção é consciente, o projeto tem por pressuposto que a história oficial de parte das denominações protestantes não contempla personagens e narrativas sobre os encontros entre política/fé/ igreja durante (e em oposição) as fases do pré-golpe e do período dos governos autoritários que se sucederam no país durante as décadas de 1960 a 1980. Assim, "Juventude, política e religião..." coloca-se como local de emersão dessas relações. Este argumento aparece na seção de "justificativas" do projeto:

As experiências de envolvimento desses, então, jovens no interior do movimento estudantil cristão protestante nas décadas de 1950 e 1960, ao lado da

7. Algumas informações sobre a formação/ atuação acadêmica dos coordenadores podem ser encontradas no próprio projeto. Contudo, uma breve pesquisa na Internet com seus nomes completos revela o envolvimento com atividades religiosas e sociais. Por exemplo, Alexandre Brasil Fonseca participou da criação do Conselho Nacional de Juventude (Conjuve), representando o Movimento Evangélico Progressista (MEP), e é membro fundador da Rede FALE - rede da juventude evangélica que, posteriormente, viria a integrar esse Conselho. Flavio Conrado é pesquisador associado do ISER, membro da Coordenação Nacional da Rede FALE e editor da revista eletrônica Novos Diálogos. 
atuação do Setor de Responsabilidade Social da Igreja são o foco desse projeto. A partir da reunião de depoimentos desses atores, hoje com idades variadas entre 60 e 80 anos, esperam-se reunir informações e experiências que servirão de subsídio para as gerações atuais acerca da participação sócio-política de jovens, que no caso, atuavam na esfera das igrejas evangélicas. Essa peculiaridade é importante de ser ressaltada, inicialmente pela repressão que estes grupos enfrentaram no seio da própria igreja, ao lado do apoliticismo que demarcou este grupo nos anos seguintes. Além destes elementos, também chama atenção a pouca bibliografia sobre o tema, ao lado do desconhecimento no interior das próprias igrejas evangélicas dessa sua história de participação social. ${ }^{8}$

Em outro trecho, o tom é ainda mais enfático:

Parece-nos uma importante contribuição para a formação e conhecimento desses jovens da história de militância e envolvimento de jovens de outras gerações que foram perseguidos e que tiveram seu histórico praticamente anulado no interior das comunidades religiosas contemporâneas. ${ }^{9}$

É com essas bases e evidências, portanto, que se coloca a afirmativa de que o projeto nasce engajado, conscientemente posicionado, e o documentário audiovisual é uma estratégia para contar histórias que não aparecem nas publicações oficiais de parte das denominações protestantes que participaram como personagens ativos, às vezes repressores. ${ }^{10}$

Embora o projeto não se preocupe em justificar a escolha do documentário como estratégia - exceto em uma passagem comparativa, com o método ver-julgar-agir da Pastoral da Juventude - a opção é intri- gante. Um exemplo de análise que poderia justificar esta escolha e instiga a reflexão sobre o projeto é a de Cássio dos Santos Tomaim (2009), que utiliza o longa-metragem "Vlado, trinta anos" para estabelecer relações entre documentário e memória afetiva. A partir de Walter Benjamin, ele afirma que o documentário é um "lugar de memória", "um refúgio em imagens e sons dos traços ou restos de uma memória viva, da 'verdadeira imagem do passado'; portanto, uma atividade de luto que não permite que estes rastros se apaguem, desapareçam, sejam esquecidos" (p. $55)$.

O caráter de resistência também é destacado por Tomaim (2009), que acredita existir essa qualidade em todo filme documentário ou cinema de não-ficção: "Trata-se de uma luta contra o esquecimento e a denegação, de uma representação engajada do mundo" (p. 55). Quando cita o filme "Vlado...", ele chama a atenção para o recurso utilizado pelo cineasta, iniciando o documentário com um “povo fala”, em que pergunta sobre Vladimir Herzog. A estratégia de narrativa, segundo o autor, revela o desconhecimento do cidadão comum sobre episódios recentes da história do país e também "o quanto o esquecimento já operou na construção do nosso passado” (p. 62). O projeto aqui analisado possui a mesma direção das iniciativas atuais de memória da opressão infringida pela ditadura no país. O recorte religioso, protestante, soma-se aos esforços de outros grupos que têm procurado canais para fazer ressoar suas histórias e suas dores. ${ }^{11}$

O argumento de Tomaim (2009) é que a dimensão afetiva, no documentário, é uma resistência ao apagamento e ao silenciamento sobre a ditadura militar, ${ }^{12}$ pois o documentário tem o poder de vasculhar "as inscrições afetivas da memória que, aliás,

\section{Juventude, política e religião - Projeto de estudo e intervenção (ISER, 2009).}

\section{Id., Ibid.}

10. Outro trecho que deixa essa questão evidente é a apresentação do objetivo geral: "Produzir recursos de formação para organizações religiosas de juventude através do resgate e análise da memória social relacionada à participação da juventude cristã na sociedade brasileira em meados do século XX". E ainda como objetivos específicos: "disseminar essa memória através de textos, vídeos e internet, tornando-a conhecida por jovens lideranças que reajam a ela; "motivar a participação social de jovens a partir do conhecimento de histórias e experiências de envolvimento de grupos organizados ligados à Igreja Evangélica em meados do século passado, estabelecendo diálogos intergeracionais". No mesmo sentido, ver: Cardoso (2011).

11. Como parte do trabalho da Comissão Nacional da Verdade, importa destacar, em relação ao projeto em foco, o grupo de trabalho intitulado "Papel das Igrejas durante a Ditadura" (http://www.cnv.gov.br/index.php/2012-05-22-18-30-05/veja-todos-os-grupos-de-trabalho/28-papeldas-igrejas-durante-a-ditadura). Outros exemplos são importantes são: Grupo Tortura Nunca Mais (http://www.torturanuncamais-rj.org.br/); Projeto Mércia Albuquerque, da DHnet-Rede de Direitos Humanos e para a Rede Estadual de Direitos Humanos-RN (http://www.dhnet.org.br/ memoria/mercia/contatos/apresenta.htm); Associação Brasileira de Anistiados Políticos (http://www.anistiapolitica.org.br/); Fundação Maurício Grabois (http://www.fmauriciograbois.org.br/); o Centro de Documentação Eremias Delizoicov e a Comissão de Familiares dos Mortos e Desaparecidos Políticos, que organizaram o site http://www.desaparecidospoliticos.org.br/; entre outros.

12. Ocorreram avanços nos últimos anos, inclusive com iniciativas dos governos federal e de diversos estados, como o portal Memórias Reveladas (www.an.gov.br), a criação e abertura de arquivos de Forças de Segurança estaduais, e da Ordem dos Advogados do Brasil (OAB), como a Campanha pela Memória e pela Verdade (http://www.oab-rj.org.br/memoria.jsp). Mesmo assim, ainda há muitos empecilhos a disponibilidade de documentos - embora nem todos tenham natureza claramente política. O tema é atual e avanços e retrocessos se constatam a cada momento. Neste sentido, ver: Valente; Leitão (2013) e Folha de S. Paulo (2013). 
são duradouras" (p. 63). Nesta perspectiva, o projeto ainda pode ser percebido como uma reivindicação protestante à participação na história do país. Aqui vale citar que o crescimento numérico e de visibilidade desse segmento social é recente. A história desse grupo no Brasil é marcada por hostilidades, como a proibição de templos possuírem arquitetura que os identificassem como igrejas e de enterros serem realizados em cemitérios católicos - que eram predominantes, e até mesmo há casos de cartórios que se recusavam a legitimar o casamento realizado por reverendos protestantes. ${ }^{13}$

Em 1962, enquanto a Confederação Evangélica do Brasil (CEB) realizava a Conferência do Nordeste em Recife (PE), da qual participaram palestrantes não-religiosos, como Gilberte Freyre e Celso Furtado, no interior de Minas Gerais um padre católico liderava um levante contra uma igreja protestante local, o que acabou em tiros e pedradas (Última Hora, 1962). Essa reivindicação pela participação na história nacional ocorre no âmbito da resistência, do não-oficial, do subterrâneo, em uma direção política progressista, e que, se nem sempre é bem-vinda nos círculos sociais do país, não ganha maior simpatia entre as cúpulas de algumas dessas igrejas, ainda nos dias atuais. As relações entre a concepção e a produção do projeto e o contexto sociopolítico do país remetem a noções de Halbwachs (2006), compiladas e trabalhadas em Memória Coletiva. Para usar uma expressão cunhada posteriormente por Michael Pollak (1989), o projeto trata de memórias subterrâneas. No entanto, não o faz de modo isolado, e sim simultaneamente a outras iniciativas semelhantes, a partir de um recorte específico. Essa relação entre questões do grupo e o contexto amplo pode ser compreendida com o que Halbwachs denomina quadros sociais da memória, ou seja, a própria emergência do projeto pode ser percebida como um impulso coletivo, um recorte que também está dentro de um grupo/quadro específico, no caso, protestante-evangélico-social e politicamente engajado. A dinâmica forjada para as gravações novamente reforça o aspecto coletivo da memória: o entrevistado é interpelado por pessoas mais jovens, de diferentes áreas do conhecimento, mas que, em sua maioria, compartilham a fé e o engajamento sociopolítico. Disso é possível imaginar a construção de uma série de referências comuns entre entrevistado e entrevistadores, embora a diversidade do grupo tenha sido pensada para também gerar deslocamentos. Contudo, até mesmo esse deslocamento é limitado pelo que há em comum, o que, além de dar ao projeto seu recorte, também funciona como enquadramento social ou, como Halbwachs (2006) prefere nomear no final de sua obra, "correntes de pensamento".

A dinâmica das gravações, a ação de colocar o entrevistado em meio a um grupo, facilita a construção coletiva da memória do período recortado, já em relação aos interesses de outra geração, em contexto diferenciado. Halbwachs (2006, p. 69) adverte:

Se a memória coletiva tira sua força e sua duração por ter como base um conjunto de pessoas, são os indivíduos que se lembram, enquanto integrantes do grupo. Desta massa de lembranças comuns, umas apoiadas nas outras, não são as mesmas que aparecerão com maior intensidade a cada um deles. De bom grado, diríamos que cada memória individual é um ponto de vista sobre a memória coletiva, que este ponto de vista muda segundo o lugar que ali ocupo e que esse mesmo lugar muda segundo as relações que mantenho com outros ambientes.

O modo como o projeto é construído em torno das lembranças da Conferência do Nordeste ${ }^{14}$ remete à percepção do pensador de que quem lembra é o indivíduo, que diferentes indivíduos possuem diferentes perspectivas do mesmo fato/evento e que, ainda assim, essas memórias individuais existem em relação à vida social.

Destacam-se três concepções sobre a memória, distinguidas no pensamento de Halbwachs (2006), que, presentes no formato e nas noções às quais remetem "Juventude, política e religião...", reforçam o argumento de que a proposta nasce engajada na elaboração da memória em um sentido determinado. A primeira é a noção de que memória é reconstrução do passado, e não evocação. $O$ projeto propõe não somente a reconstrução, mas o modo de fazê-la, quem trabalha nessa obra e para quem ela é destinada. Outra concepção pode ser sintetizada na afirmação de que o presente é o ponto de partida para essa reconstrução e que, uma vez apresentado o projeto e seus objetivos, não é necessário estender-se nesse ponto. Por fim, Halbwachs percebe que a memória é dinâmica, não pode ser cristalizada, ela se modifica e se molda a uma infinidade de variáveis - e o grupo social é elemento impulsionador desses movimentos transformadores. Ao assumir que parte do presente, é também necessário considerar tal caráter dinâmico da memória.

13. Neste sentido, é interessante consultar texto do historiador oficial da Igreja Presbiteriana do Brasil, Alderi Souza Matos, "Até a Proclamação da República, os protestantes enfrentariam sérias restrições no que diz respeito ao casamento civil, uso de cemitérios e educação". Disponível em: <http://www.mackenzie.br/6994.html>. Acesso em: abr. 2013

14. Também foram e serão entrevistados atores que não participaram diretamente da Conferência, mas que possuem alguma relação com outros entrevistados que nela tiveram participação ativa. 


\section{Coesão ou oposição: até onde o projeto pretende/ pode chegar? Ou como colorir o presente com o passado}

O modo de realização do projeto - tanto no que se refere à presença de um grupo de entrevistadores mais jovens do que os entrevistados e com perfis conscientemente selecionados quanto ao modo de edição, a partir do olhar de jovens do século XXI - coloca-se como uma proposta de elaboração do passado por meio do presente. Em nenhum momento o texto que apresenta a proposta, objetivos e justificativas evoca a ideia de que pretende reescrever o passado tal qual ele foi; pelo contrário, há a intenção de interação entre presente e passado. Para retomar a expressão de Pollak (1989), é a aquarela do presente que fornece as cores ao passado e, neste caso, tudo é pensado para que seja exatamente dessa forma.

Essa intencionalidade presente no projeto remete à noção de trabalho de memória. Se o simples fato de lembrar já é coletivo, como aponta Halbwachs (2006), para Pollak (1989) existe um esforço de grupos sociais para o enquadramento da memória. $\mathrm{O}$ projeto pode ser compreendido, nesta perspectiva, como um esforço do grupo de protestantes que compartilham certas visões políticas e sociais, que vai de encontro ao enquadramento da memória realizado pelos protestantes em geral, por aqueles que, de dentro do grupo, têm condições de determinar a história oficial do protestantismo no país. Neste sentido, a memória é elaborada sempre mediante um esforço, um "trabalho", pois essa ou aquela elaboração não é dada "naturalmente", é disputada. Assim, ao trabalho de enquadramento da memória se opõe o trabalho a partir da história oral, para a emersão da história subterrânea, que pode contestar a história oficial.

A memória nacional, para Pollak (1989), é o exemplo de enquadramento da memória, visto que esta é organizada para a formação de um determinado sentido, que possui força para se impor como oficial sobre outras narrativas possíveis. É em relação a isso que o pesquisador coloca que a história oral, por privilegiar "a análise dos excluídos, dos marginalizados e das minorias", revela "a importância de memórias subterrâneas que, como parte integrante das culturas minoritárias e dominadas, se opõem à 'memória oficial', no caso a memória nacional" (p. 4). Em "Juventude, política e religião...", é possível transportar essa análise da constituição de uma memória nacional para o microcosmo institucional das igrejas protestantes que, assim como "a nação", buscam um certo tipo de memória para construir suas histórias oficiais. ${ }^{15}$

A relação entre maioria, "oficial", e minoria evidencia-se, também, nos depoimentos coletados. Pollak (1989, p. 5) mostra como, no trabalho que realizou com sobreviventes de campos de concentração, os entrevistados evitam ser agressivos com os grupos - claramente majoritários - opressores: "Não provocar o sentimento de culpa da maioria torna-se então um reflexo de proteção da minoria judia". No vídeo já produzido pelo projeto, o personagem usa a expressão "setores da igreja, da cúpula da igreja, deram o golpe antes do golpe" [grifos nossos]. O cuidado ao fazer essa colocação revela a preocupação de não lançar a culpa sobre a totalidade da igreja. Em outro depoimento, ainda não editado, o entrevistado ressaltou que, se por um lado, ele foi entregue à polícia (o que redundou em 30 dias de tortura e exílio do país por nove anos) por um líder da igreja que frequentava, por outro também recebeu apoio de vários outros membros da comunidade. Esses são apenas alguns de vários outros exemplos que poderiam ser retirados das mais de 40 horas de gravação.

Percebe-se, assim, que entre os tons pretendidos pelo projeto estão as cores fortes, que procuram delinear uma memória esquecida dentro do universo protestante brasileiro. Por outro lado, o projeto soma-se a outros movimentos que buscam revolver histórias da opressão durante as ditaduras e reconstruir a história do país, no contexto amplo das disputas pela memória nacional. Neste sentido, também aparecem - sem ênfase na apresentação do projeto, portanto, de forma bem mais diluída - os tons que procuram colorir em harmonia com outros grupos que possuem o mesmo tipo de luta e, em contraste, disputa com os traços da história nacional. Pollak (1989, p. 11-12) observa que uma sociedade abriga

memórias coletivas tão numerosas quanto as unidades que compõem a sociedade. Quando elas se integram bem na memória nacional dominante, sua coexistência não coloca problemas, ao contrário das memórias subterrâneas [...]. Fora dos momentos de crise, estas últimas são difíceis de localizar e exigem que se recorra ao instrumento da história oral. Indivíduos e certos grupos podem teimar em venerar justamente aquilo que os enquadradores de uma memória coletiva em um nível mais global se esforçam por minimizar ou eliminar.

Assim, a memória subterrânea evocada pelo projeto não se opõe somente ao grupo religioso. Talvez 
seja possível afirmar que essas instituiçõs religiosas enquadraram sua própria memória oficial dentro da memória nacional, aquela que pretende forçar o esquecimento do passado recente de arbitrariedade, totalitarismo, restrição da liberdade e tortura. E, como mostra o filme "Vlado, trinta anos depois", essa força que alisa a superfície da história tem predominado no país. Dar voz aos torturados, aos exilados, aos que tiveram parte de sua vida brutalmente rompida é um processo ainda em construção pelas políticas nacionais de memória. Na contramão do processo consolidado pela Comissão Nacional de Verdade, vale a pena ressaltar a também recente decisão do Supremo Tribunal Federal $(\mathrm{STF})^{16}$ ao recusar rever a "Lei de Anistia”, sustentando o entendimento de que essa lei teria anistiado os crimes de tortura cometidos por agentes estatais contra presos políticos durante o período da ditadura militar (1964-1985). A decisão, para além dos debates que a precederam, ${ }^{17}$ aparentemente teria encerrado as possibilidades de sanções penais e de reparação histórica às milhares de vítimas do regime autoritário. Ao mesmo tempo, repercutiu em outras questões políticas nacionais, como a discussão sobre a abertura dos arquivos históricos do período militar. Esses fatos podiam, à época, ser percebidos como forma de manter no esquecimento parte da memória nacional, com a estratégia do silêncio, do desconhecimento. A história oral, segundo Pollak (1989), é capaz de fazer aparecer "os limites desse trabalho de enquadramento" (p. 12).

A reflexão realizada, portanto, revela movimentos que se tensionam e podem ser expressos pelos pares coesão/oposição e interno/externo. A coesão mostra-se na relação possível de ser estabelecida com outros grupos e iniciativas que têm promovido a memória dos prejudicados pelos governos totalitários no Brasil. Já o movimento de oposição aparece tanto na relação com a memória oficial interna ao segmento religioso quanto, no contexto amplo, com a memória nacional. Ainda é possível perceber efeitos - que o projeto declaradamente pretende gerar - de coesão dentro do próprio grupo. Interessante que, ao conseguir esse efeito de coesão, o movimento de oposição interna fica imediatamente fortalecido. Esses efeitos podem ser provocados pela "ligação fenomenológica muito estreita entre a memória e o sentimento de identidade" que, segundo Pollak (1992), ocorre quando se trata da "memória herdada" (p. 204).

\subsection{Os tons da identidade: fronteira, tempo e coerência}

"Passar adiante" a memória elaborada da participação política de protestantes nos anos 60 e 70 do século passado; colocar essa elaboração à disposição daqueles que, na atualidade, se colocam em lugar semelhante, ou, talvez, criar a sensação de que esse lugar não está vazio de passado são propostas de "Juventude, política e religião...". Considerando, portanto, que esses elementos compõem a construção de uma herança, com o intuito de repassá-la às gerações atuais e subsequentes, pode-se pensar esta proposta a partir dos três elementos que Pollak (1992) aponta para a construção da identidade, emprestados, segundo o pesquisador, pela psicologia social e pela psicanálise. O primeiro é a fronteira, o limite do grupo ou individual, "o sentimento de ter fronteiras físicas, no caso do corpo da pessoa ou fronteiras de pertencimento ao grupo, no caso de um coletivo" (p. 204). Pode-se perceber no projeto uma intenção de expandir a fronteira de pertencimento ao grupo protestante evangélico: ao buscar no passado a legitimidade para determinadas ações políticas e sociais reforça-se o pertencimento dos jovens alvos do projeto e coloca-se dentro do grupo as personagens desta história retomada.

O segundo elemento necessário é o tempo, o sentimento de "continuidade dentro do tempo, no sentido físico da palavra, mas também no sentido moral e psicológico" (Pollak, 1992, p. 204). A relação aqui é bastante óbvia, pois o diálogo entre as gerações, que o projeto intenta provocar, tem por objetivo final a ação na atualidade, ou seja, os jovens podem sentir que o lugar ocupado agora, sua identidade (protestante, evangélico, atuante política e socialmente) é uma continuidade no tempo, pois já existia antes de seu envolvimento individual. Por fim, a coerência é outro elemento constitutivo de identidade que pode ser oferecido pela memória e está intimamente ligado ao tempo. Ao ocupar esse espaço e saber que ele já foi ocupado antes, o jovem pode sentir que as diferentes características/lugares que o formam são unificados. Ao apresentar esses elementos, Pollak argumenta que a memória é um importante aspecto que constitui o sentimento de identidade, "na medida em que ela é também um fator extremamente importante do sentimento de continuidade e de coerência de uma pes-

16. Lei n. 6683/79, ADPF n.153. A decisão foi divulgada no dia 14 de abril de 2010.

17. A Associação de Juízes para a Democracia (AJD), por exemplo, promoveu uma série eventos e debates, incluindo a coleta de assinaturas em campanha contra a "anistia para os torturadores, sequestradores e assassinos dos opositores à ditadura militar", conforme divulgação no site da associação. A campanha, que culminou com manifesto a ser entregue ao Ministro Gilmar Mendes, coletou - segundo e-mail enviado pela AJD às vésperas do julgamento da ADPF 153 -, mais de 15.800 assinaturas de apoio. Disponivel em: <http://ajd-brasil.blogspot.com/>. Acesso em: 15 maio 2010. 
soa ou de um grupo em sua reconstrução de si" (p. 204). "Reconstrução", certamente, é o que está em jogo no projeto analisado.

\subsection{Os riscos do esquecimento e da deformação}

O reforço do pertencimento ao grupo, a oposição a memórias oficias enquadradas e a constituição/ reforço de identidade são algumas cores do presente que estão na composição que se pretende fazer com as narrativas dos personagens do projeto. No entanto, a busca pela elaboração dessa memória e o engajamento com que isso é realizado apresentam riscos que colocam em questão até onde esse tipo de iniciativa pode ir. Pollak (1989, p. 9) atenta para a facilidade de deformação da memória, especialmente nas reminiscências de momentos conturbados:

Distinguir entre conjunturas favoráveis ou desfavoráveis às memórias marginalizadas e de saída reconhecer a que ponto o presente colore o passado. Conforme as circunstâncias, ocorre a emergência de certas lembrancas, a ênfase é dada a um ou outro aspecto. Sobretudo a lembrança de guerras ou de grandes convulsões internas remete sempre ao presente, deformando e reinterpretando o passado. Assim também, há uma permanente interação entre o vivido e o aprendido, o vivido e o transmitido.

Neste ponto é interessante perceber a ousadia e os riscos das propostas e mesmo dos métodos escolhidos pelo projeto, que aposta na reinterpretação do passado. Essa aposta pode ser traduzida em potencial e em ameaça, pois trata-se de elaboração interessada da memória, feita por jovens sobre histórias as quais não teriam acesso, e que, talvez, não sejam contadas de outra maneira.

O vídeo "Cristo e o processo revolucionário brasileiro”, que é o primeiro resultado de edição do projeto, finaliza com o personagem Waldo César perguntando ao grupo de entrevistadores e à equipe técnica: "Agora eu que pergunto: e o que vocês vão fazer com isso tudo?" A pergunta ainda não pode ser respondida, já que o projeto não concluiu, até o momento da finalização da presente análise, a edição das demais entrevistas realizadas. Portanto, não há como saber o resultado da interação desse conteúdo com os jovens da atualidade. A proposta certamente traz à tona dois riscos abordados por Pollak (1989), que são o esquecimento e a deformação da memória, que, conforme já apontado, são mais intensos nas reminiscências de momentos conturbados.

O esquecimento, especificamente neste projeto, pode ocorrer já na fase de coleta. Os personagens podem deixar passar coisas que seria importante regis- trar. Se, por um lado, a dinâmica da entrevista grupal facilita o surgimento de assuntos diversos, por outro pode bloquear algumas lembranças. Pollak (1989) chama a atenção para as "zonas de sombra, silêncios, não-ditos" que existem em algumas pessoas. O esquecimento pode ser reprimido inconscientemente e ser definitivo. Para ele, essa tipologia de discursos que inclui silêncios, pausas, alusões e metáforas "é moldada pela angústia de não encontrar uma escuta, de ser punido por aquilo que se diz, ou, ao menos, de expor a mal-entendidos" (p. 8).

Na reelaboração de memória que pretende fazer, o projeto ainda se depara com outro obstáculo, que advém do silêncio: os personagens que decidem não falar. Para Pollak (1989), quando não há possibilidade de se fazer compreender, "o silêncio sobre si próprio - diferente do esquecimento - pode mesmo ser uma condição necessária presumida ou real para a manutenção da comunicação com o meio-ambiente" (p. 13). Ele narra que essa foi a opção, por exemplo, de uma sobrevivente judia de campos de concentração, que escolheu permanecer na Alemanha.

Em "Juventude, política, religião...", pelo menos uma das personagens tomou essa posição. Pollak (1989) analisa que, como a memória é "indissociável da organização social da vida", o modo de lembrar é o que faz sentido para o indivíduo, de tal forma que o coloca em algum lugar na sociedade. Sendo assim, a decisão pelo silêncio pode ser interpretada como uma negação ao enquadramento que aquela memória necessariamente receberá, uma vez que venha à tona. A memória "não escapa ao trabaho de definição de fronteiras sociais" (p. 14), e, no caso do projeto, é de fronteiras - seja fortalecimento, seja ampliação - de que se trata.

O esquecimento definitivo pode ser o destino do que poderia ter sido dito por aqueles que se recusaram a falar. Além desse esquecimento, partes importantes dos depoimentos, em relação ao grupo social e à oposição às memórias enquadradas, podem ser ignoradas pelos editores do material e, assim, destinadas ao esquecimento. Este, no entanto, pode ser provisório, visto que o material bruto ficará disponível para pesquisa. Na verdade, a repercussão das gravações é difícil de mensurar ou prever. Também há o risco da deformação dessas memórias. Por "deformação" compreende-se a apropriação dessas memórias, de forma a colocá-las em quadros preestabelecidos, ou seja, enquadrá-las, em vez de questionar os enquadramentos dados. Contudo, do modo como este tema é apresentado por Pollak, o risco de deformação está presente em toda e qualquer proposta de visibilidade para memórias subterrâneas.

Outro autor importante para os estudos de memória, Tzvetan Todorov (2000), denomina esse comportamento de "abuso da memória". Para ele, há 
muitos usos que podem ser feitos da memória, mas também existem abusos. ${ }^{18}$ No caso brasileiro, o próprio silêncio a que aspectos da história estão condenados forçosamente se encaixa na definição de abuso.

A aposta do projeto é que, ao confiar a produção e a edição aos olhos e mãos de jovens evangélicos e pesquisadores da atualidade, o efeito seja exatamente o oposto: a potencialização contestatória deste material, e não a deformação amenizadora desse potencial - que parece ser a preocupação de Pollak. A proposta é que a juventude dê o colorido aos depoimentos, organize o seu sentido de acordo com as reivindicações da atualidade. É um projeto que propõe a construção de sentido, e não recolher e distribuir um amontoado de narrativas datadas. Pelo engajamento do projeto, já referido, é possível que esse risco especificamente, o da deformação, tenha sido avaliado pelos propositores.

Considerando o contexto apontado, percebe-se que a aposta do projeto é que esses jovens se apropriem dessa memória para reivindicar, às insituições religiosas e à sociedade, o seu espaço de atuação política; assim, de certa forma, isso pode proteger essas histórias tanto do esquecimento definitivo quanto da deformação abusiva pelos atuais construtores da história oficial. O que será decisivo, portanto, é a seleção - a decupagem de conteúdo - a ser realizada por pesquisadores e jovens evangélicos, seguida pela edição de profissionais. Pollak (1989, p. 9-10) chama a atenção:

O trabalho de enquadramento da memória se alimenta do material fornecido pela história. Esse material pode sem dúvida ser interpretado e combinado a um sem-número de referências associadas; guiado pela preocupação não apenas de manter as fronteiras sociais, mas também de modificá-las, esse trabalho reinterpreta incessantemente o passado em função dos combates do presente e do futuro.

O que está em questão na proposta de "Juventude, política e religião..." é a ampliação do material histórico disponível, o deslocamento dos quadros atuais. A expectativa parece ser a de que o trabalho de reinterpretação possa expressar os combates atuais e, de alguma forma, desequilibrar a balança que pende para a história oficial. Potencialmente, o projeto oferecerá, aos jovens evangélicos politicamente engajados da atualidade, matéria-prima para a construção de identidade, já que, como apontado anteriormente, é provável que esse subgrupo tenha dificuldade de se identificar com o grupo a que pertence. Contudo, os dados disponíveis até o momento não permitem ir muito além nesse aspecto do projeto, visto que essa etapa ainda não ocorreu. Neste sentido, pode ser válido, após a finalização deste trabalho, comparar as gravações brutas com as seleções realizadas por esses jovens editores e pesquisadores.

\section{A técnica como lugar de "diálogo intergeracional": o sensorial e encontros de temporalidades}

"O documentário nos lembra aquilo que gostaríamos de ter esquecido", aponta Tomaim (2009, p. 53), quando procura pensar as relações entre memória afetiva e documentário. O argumento evocado é que o videodepoimento é a forma privilegiada para trazer à luz as memórias difíceis de tocar. Assim, o audiovisual seria esse "refúgio" sensível, sensorial, dos restos da imagem do passado. Portanto, o documentário não tem o poder de copiar o passado, mas de trazer - em referência clara ao pensamento de Walter Benjamin - os restos, os rastros que não estão apagados. Além disso, essa irrupção do passado não está tanto na narrativa racionalizada, realizada de modo cronológico ou temático, quanto nas expressões sensoriais - nas rugas que aparecem na face, nos olhos apertados, no silêncio, nas pausas, no interdito, em dedos retorcidos, em uma palavra: gestos.

Pollak (1989, p. 119) também reconhece que "nas lembranças mais próximas, aquelas de que guardamos recordações pessoais, os pontos de referência geralmente apresentados nas discussões são [...] de ordem sensorial, o barulho, os cheiros, as cores". Exatamente por dirigir-se "não apenas às capacidades cognitivas", mas igualmente captar as emoções, o pesquisador reconhece no filme "o melhor suporte" para trazer à tona as lembranças. Na sequência, Pollak coloca que "o filme-testemunho e documentário tornou-se um instrumento poderoso para os rearranjos sucessíveis da memória coletiva e, através da televisão, da memória nacional" (p. 11). Desta forma, esse tipo de produção pode ser utilizada tanto com o objetivo de deslocar enquadramentos estabelecidos quanto tem sido sistematicamente utilizada para enquadrar e reenquadrar a memória oficial. ${ }^{19}$

18. Como apresentado na Introdução, este artigo abre janelas para outras possibilidades de reflexão, a partir do projeto aqui analisado e, certamente, o pensamento de Todorov seria um caminho possível que, no entanto, ficaria mais consistente se somado a outros elementos. Para a presente reflexão, preferiu-se seguir o caminho indicado por Pollak, com contribuições de Halbwachs.

19. Uma reflexão sobre a televisão e a construção da história nacional foi apresentada por um dos autores no III Congresso de Estudantes de Pósgraduação em Comunicação (Coneco) 2008, sob o título "A minissérie 'A Muralha' e a construção da nacionalidade brasileira no século XXI". 
De qualquer forma, é interessante que o projeto lance mão desse recurso para buscar os resultados esperados e coloque o vídeo - uma técnica, um recurso tecnológico - nesse lugar de possibilidade de captar para além do cognitivo; de apreender, preservar, guardar; de possibilitar a reinterpretação; de encontro entre passado e presente. A noção de que, no documentário, o passado - ou seus rastros e restos - irrompe no presente é interessante porque supõe intersecção entre diferentes momentos temporais. Essa emersão do passado não rompe com o presente e o transporta para um tempo anterior, mas promove um certo tipo de descontinuidade que é, ao mesmo tempo, prosseguimento do presente. É um ponto de indecisão. Neste sentido, para a promoção de "diálogos intergeracionais", como propõe o projeto, o filme apresenta-se como o suporte adequado, já que, por si só, permite o encontro entre passado e presente. Quando o público-alvo é jovem, pode-se inferir que esse encontro ainda vislumbre um efeito de/para futuro. A gravação é uma forma de permanência, por isso, encontro de temporalidade, de apreender as narrativas para que o registro possa permanecer para além da própria personagem. Novamente, essa perspectiva faz lembrar os riscos desse tipo de proposição e, paralelamente, o seu potencial.

Seguir a pista da intersecção de temporalidades remete às reflexões de Andreas Huyssen sobre a contemporaneidade e, neste sentido, é possível compreender o surgimento de "Juventude, política e religião..." como integrante do movimento de busca pelo passado que o autor identifica na atualidade. Para Huyssen (1997), a temporalidade contemporânea é configurada por dinamismo e efemeridade e alimentada pela aceleração temporal. Na mesma direção, o espanhol-colombiano Martin-Barbero acredita que esta temporalidade pode ser caracterizada pela amnésia, aceleração e autismo. Essa ausência de passado, este tempo fechado em si mesmo geraria, em contrapartida, um "boom de memória", que pode ser observado na quantidade de filmes históricos lançados nos últimos anos, nos investimentos em restauração de prédios, na procura por museus.

Ora, o projeto pode ser colocado neste contexto de "febre de memória" e "desejo de passado" (Martin-Barbero, 2000). O boom de memória pode ser interpretado como uma reação ao presente focado na atualidade. Talvez uma tentativa de construir uma ponte capaz de libertar o presente de seu autismo. Para Martin-Barbero, há uma relação entre essa necessidade de retornar ao passado, de recordar, e a aceleração gerada pelos processos técnicos. Para Huyssen (1997, p. 18), a memória é a tentativa de diminuir o ritmo do processamento de informações, de resistir à dissolução do tempo na sincronicidade do arquivo, de descobrir um modo de contemplação fora do universo da simulação, da informação rápida e das redes de TV a cabo, de afirmar algum 'espaço-âncora' num mundo de desnorteante e muitas vezes ameaçadora heterogeneidade, não-sincronicidade e sobrecarga de informações.

Tanto Martin-Barbero (2000) como Huyssen (1997) chamam a atenção para a possibilidade de essa febre de memória e esse desejo de passado não serem simplesmente reativos e, neste caso, podem ser percebidos como atitude crítica à tecnicidade e, portanto, como contestação. Por outro lado, a reação ao aceleramento do ambiente técnico pode ser ressentida e gerar voltas rancorosas ao passado, como os movimentos que retomam teorias políticas e econômicas ultrapassadas e posturas sociais de intolerância. Assim, a proposta alternativa seria pensar amnésia e memória como complementares, e não mais de modo maniqueísta. Para Martin-Barbero (2000), o hibridismo e a multiplicidade podem enfocar a tensão entre memória e esquecimento, e é exatamente na tensão que o autor percebe desafios e aponta esperanças que - sem cair no que seria um retrocesso de fundamentos históricos ou garantias futuras, um ponto de chegada - acredita possível serem construídas como caminho.

A participação ativa dos jovens na edição do projeto pode suscitar essa tensão da memória e do esquecimento. Vale lembrar que a memória é seletiva e, certamente, esses jovens devem selecionar o que querem guardar das histórias narradas. $\mathrm{O}$ projeto propõe, portanto, o encontro entre uma geração que acreditou na história e no futuro, a ponto de morrer e sacrificar-se por ele, e uma geração que vive no contexto high-tech do achatamento do tempo. Nesse encontro reside o risco e a tensão entre passado, presente e futuro: olhos do presente reconstruirão os modos como serão contadas e interpretadas as narrativas do passado. O simples interesse dos jovens de trabalhar com essas narrativas revela a procura, talvez a necessidade, de lastro no passado, de uma memória que oferece legitimidade para as ações no presente. Um encontro que abriga a ameaça do esquecimento e da distorção, da limitação aos atuais e restritivos quadros de memória, e simultaneamente abriga o potencial da resistência, do questionamento e deslocamento das molduras construídas arbitrariamente no silêncio imposto, na invisibilidade; o potencial de articular passado e futuro de formas inéditas, em que, para Martin-Barbero (2000), reside a possibilidade de caminhos criativos, não excludentes, para a contemporaneidade lidar com memória e esquecimento. 


\section{Considerações finais}

O percurso desta análise traz à tona algumas considerações específicas sobre o projeto "Juventude, política e religião: uma abordagem dialógica". A reflexão sobre esta proposta, à luz das teorias utilizadas, possibilita perceber lugares nos quais o projeto se insere e pressupostos com que trabalha. Como apresentado, a partir de trechos da proposta, "Juventude, política e religião...” parte da concepção de elaboração de memória, e não de reconstituição; tem ainda, como pressuposto, a dinamicidade dessa memória e, como consequência disso, a possibilidade de apropriação e uso desse passado elaborado pelo presente. Como lugar, percebe-se que o projeto insere-se no contexto de reivindicação da memória de pessoas e grupos perseguidos e vitimizados pelas ditaduras no país. Pode-se dizer ainda que, enquanto se soma a outras reivindicações semelhantes, também se coloca no lugar de luta por uma memória abafada pelas histórias oficiais - seja no contexto macro, da memória nacional (aqui a soma é necessária), seja dentro do grupo evangélico protestante que aparentemente procura convergir à memória do grupo à história oficial do país. Neste sentido é que se apresentam os movimentos de tensão coesão/oposição e interno/externo. Ao questionar a memória do grupo, procura-se, ao mesmo tempo, a integração do subgrupo, seu atestado de pertencimento e realocação dentro do contexto amplo.

A elaboração da identidade, que ocorre mediante a apropriação da memória, contribui fortemente com esses movimentos, especialmente no que concerne aos aspectos internos ao grupo. O conhecimento e possibilidade de apropriação da memória trabalham com os três elementos que Pollack $(1989,1992)$ identifica como fundamentais para a formação de identidade: fronteira, tempo e coerência. A disponibilização dessas narrativas tem o potencial de criar nos jovens o sentimento de pertencimento ao grupo, já que, a partir de então, a atuação na atualidade pode ser eco do passado. Não é necessário filiar-se a outro grupo para assumir determinados posicionamentos políticos, já que eles existiram anteriormente dentro do próprio protestantismo evangélico.

O potencial de apropriação e uso da memória de "Juventude, política e religião..." é acompanhado de riscos, que podem ocorrer a qualquer momento nos processos previstos pelo projeto. $\mathrm{O}$ esquecimento definitivo de coisas não apreendidas pelo projeto ou mesmo não selecionadas pelos jovens e a deformação pela visão demasiado atual, afetada, parcial são possibilidades que a proposta contém. O deslocamento do contexto das décadas de 60 e 70 do século passado para os primeiros anos do século XXI traz potenciais importantes e riscos consideráveis. A apropriação, no entanto, não pode ocorrer sem que esses riscos sejam assumidos.

Por fim, pensar o meio que abriga essa memória e possibilita o encontro intergeracional induz a, mais uma vez, deslocar o projeto para o contexto macro: percebe-se, então, como ele pode estar inserido na busca desenfreada por lastro histórico, como sintoma do excesso de presente da cultura contemporânea. Interessante que esse trajeto, com as contribuições de Andreas Huyssen (1997, 2000) e Martin-Barbero (2000), reforça o que já podia ser visto em outros autores trabalhados mais intensamente nas primeiras partes do trabalho: o projeto abriga, potencialmente, riscos e resistência. Por um lado, aparecem as ameaças de esquecimento, distorção, de restrição ao vício do instante presente na atualidade. Por outro lado, o potencial da resistência, do questionamento e de deslocar as molduras constituídas da história oficial. A novidade, quando a questão específica do tempo entre em cena, é o encontro entre passado, presente e futuro indicar que, para além do autismo do presente, a cultura contemporânea pode articular novos caminhos e formas inéditas - possivelmente complementares - de lidar com memória e esquecimento.

\section{Referências}

CARDOSO, Rodrigo. Os evangélicos e a ditadura militar. Isto é - independente. n. 2.170, 10 jun. 2011. Disponível em: http://www.istoe.com.br/reportagens/141566_OS+ EVANGELICOS+E+A+DITADURA+MILITAR

FOLHA DE S. PAULO. Documentos da ditadura militar serão digitalizados. 02/04/2013. Disponível em: <http:// www1.folha.uol.com.br/poder/1255774-documentosda-ditadura-militar-serao-digitalizados.shtml>. Acesso em: abr. 2013

HALBWACHS, Maurice. A memória coletiva. São Paulo: Centauro, 2006.
HUYSSEN, Andreas. Memórias do modernismo. Rio de Janeiro: UFRJ, 1997.

HUYSSEN, Andreas. Seduzidos pela memória: arquitetura, monumentos, mídia. Rio de Janeiro: Aeroplano, 2000. ISER - Instituto de Estudos da Religião. Juventude, política e religião: uma abordagem dialógica - projeto de estudo e intervenção. Rede Fale de Defesa de Direitos. 2009. Disponível em <http://www.iser.org.br/site/sites/ default/files/Projeto\%20Juventude\%20Politica $\% 20 \mathrm{e} \% 20$ Religiao\%202009-2010.pdf>. Acesso em: 3 ago. 2010. LONGUINI NETO, Luiz. O novo rosto da missão: os 
movimentos ecumênico e evangelical no protestantismo latino-americano. Viçosa, MG: Ultimato, 2002.

MARTIN-BARBERO, Jesús. Dislocaciones del tiempo y nueva topografia de la memória. In: HOLLANDA, Heloisa Buarque de; REZENDE, Beatriz (Orgs.). Artelatina: cultura, globalização e identidades. Rio de Janeiro: Aeroplano, 2000.

POLLAK, Michael. Memória, esquecimento, silêncio. Estudos Históricos, Rio de Janeiro, v. 2, n. 3, p. 3-15, 1989. POLLAK, Michael. Memória e identidade social. Estudos Históricos, Rio de Janeiro, v. 5, n. 10, p. 200-212, 1992.

TOMAIM, Cassio dos Santos. O documentário como chave para nossa memória afetiva. Intercom - Revista Brasileira de Ciências da Comunicação. v. 32, n. 2, jul./dez. 2009. São Paulo: Intercom, 2009. p. 53-69.

TODOROV, Tzvetan. Los abusos de la memoria. Barcelona: Paidós, 2000.

ÚLTIMA HORA. Católicos e protestantes em conflito em Minas. Rio de Janeiro, 27/07/1962. p. 5.

VALENTE, Rubens; LEITÃO, Matheus. Documentos da ditadura são retidos por ministérios. 03/03/2013 20h00. Disponível em: <http://www1.folha.uol.com.br/ poder/1239837-documentos-da-ditadura-sao-retidos-por-ministerios.shtml>. Acesso em: abr. 2013.

\title{
"Colorea el pasado con el presente": construcción y apropiación de
} la memoria en el proyecto Juventud, política y religión: diálogos

\section{intergeneracionales}

\section{Resumen}

Éste artículo presenta un análisis de los registros del proyecto en el testimonio de vídeo de líderes evangélicos perseguidos por la dictadura militar con el fin de que los jóvenes de hoy tienen contacto con este material. Utiliza las reflexiones de Michael Pollak y Maurice Halbwachs, y la relación entre la memoria y contemporáneo temporales tejida por Andreas Huyssen y Martín Barbero. Son percibidos conflictos de identidad y pertenencia en el grupo y en el contexto más amplio de la historia oficial / memoria nacional.

Palabras clave: memoria, derecho a la memoria, documental de vídeo, religión, juventud.

\section{"To dye the past with the colors of the present": memory building and re- appropriation in the project Youth, politics and religion: intergenerational dialogues}

\begin{abstract}
The paper analyzes a project, which uses the video testimony of evangelical leaders persecuted by the military dictatorship, to develop memory building processes in young people. The theoretical framework is based on reflections by Michael Pollak and Maurice Halbwachs, and the intersections between memory and temporality drawn up by Andreas Huyssen and Martin-Barbero. It perceives struggles for identity and belonging within the group and in the broader context of the official history/national memory.
\end{abstract}

Keywords: memory, right to memory, documentary film, religion, youth.

Data de recebimento do artigo: 30/11/2011

Data de aprovação do artigo: 15/04/2013 